\title{
Usulan Perbaikan Sistem untuk Meningkatkan Kualitas Layanan Sistem Administrasi Gudang Online (AGO) Menggunakan Standar ISO/IEC 9126 di PT. PLN (PERSERO) Rayon Duri
}

\section{System Improvement Proposal in Increasing the Service Quality of Online Warehouse Administration System using ISO/IEC 9126 Standard (Case Study: PT. PLN (PERSERO) Duri Rayon)}

\author{
Muhammad Ihsan Hamdy ${ }^{1}$, Rika Rahmat Putri ${ }^{1}$ \\ ${ }^{1}$ Jurusan Teknik Industri, Fakultas Sain dan Teknologi, Universitas Islam Negeri Sultan Syarif Kasim Riau
}

\section{ARTICLE INFO}

Article history:

Diterima 14-03-2020

Diperbaiki 20-05-2020

Disetujui 27-06-2020

Kata Kunci:

Kualitas Sistem, Standar ISO/IEC 9126, Sistem AGO, Maturity Model, Delay
Keywords:

System Quality, ISO/IEC 9126 Standard, Online

Warehouse

Administration System, Maturity Model, Delay

\begin{abstract}
A B S T R A K
Dalam pembangunan sebuah sistem diperlukan adanya penjaminan kualitas. Sebuah sistem bisa dikatakan berkualitas baik apabila sudah memenuhi kebutuhan pemakai. Kualitas dapat diukur dari beragam sudut pandang. Salah satu sudut pandang untuk mengukur kualitas perangkat lunak adalah dengan berfokus kepada kepuasan pengguna (user based). Untuk mengetahui kualitas suatu sistem maka diperlukan analisis kualitas terhadap sistem tersebut. Sistem administrasi gudang online (AGO) yang digunakan untuk mengelola persedian material gudang di PT. PLN (Persero) Rayon Duri ini masih memiliki kekurang an dalam pelayanannya saat digunakan, penelitian ini bertujuan untuk menemukan usulan perbaikan guna meningkatkan persentase kualitas layanan sistem administrasi gudang online (AGO) berdasarkan standar ISO/IEC 9126. Metode pengumpulan data pada penelitian ini menggunakan metode wawancara dan kuesioner untuk mengetahui keluhan user terhadap sistem, sedangkan untuk pengolahan data menggunakan pendekatan maturity model dan delay. Dalam pengujian tingkat reliability (keandalan) sistem AGO berada pada level 1 (sistem sudah terkomputerisasi namun belum terstandarisasikan), untuk mengujian delay seluruh keterlambatan input masuk pada kategori baik dan bisa dimaklumi. Berdarsarkan level maturity (kematangan) dan delay pengujian meghasilkan bahwa sistem administrasi gudang online (AGO) memerlukan adanya perbaikan dan perawatan untuk meningkatkan kinerja kualitas layanan sistem terhadap pengguna (user), sehingga dengan adanya perbaikan dan perawatan sistem dapat meningkatkan $26 \%$ menjadi $41 \%$ persentase kualitas sebuah sistem teknologi informasi.
\end{abstract}

\section{A B S T R AC T}

In building a system, it was needed a quality guarantee. A system could be stated well qualified, if it_met the user needs. The quality could be measured from various points of views. One point of views to measure the software quality was focusing on user satisfaction (user based). To know the quality of a system, it was needed a quality analysis of its system. There was a lack of service when online warehouse administration system used to manage the warehouse material inventory in PT. PLN (Persero) Duri Rayon was used. This research aimed at finding proposed improvements for increasing the service quality percentage of online warehouse administration system based on ISO/IEC 9126 standard. The methods of collecting the data were using interview and questionnaire to know user complaints to the user. Maturity Model and Delay approaches were used to process the data. In testing the reliability level, online warehouse administration system was on the first level (the system was computerized, but it was not standardized yet). In testing the delay, all the delays in input were on good category and it could be_understandable. Based on the levels of maturity and delay, the test showed that there was a need to improve and maintenance the online warehouse administration 
system to increase the performance of system service quality for users, so that the existence of repairs and maintenance systems can increase $26 \%$ to $41 \%$ the percentage of the quality of an information technology system.

\section{Pendahuluan}

Kualitas sistem dapat diukur dari beragam sudut pandang. Salah satu sudut pandang untuk mengukur kualitas perangkat lunak adalah dengan berfikus kepada kepuasan pengguna (user based). Untuk mengetahui kualitas suatu sistem maka diperlukan analisis kualitas terhadap sistem tersebut [1].

Kualitas sistem yang baik untuk digunakan adalah keandalan sistem saat dioperasikan, sistem yang dapat menyesuaikan dengan berbagai kebutuhan pengguna dan ke kondisi yang berubah-ubah, sistem memudahkan dalam menggambungkan data dari berbagai macam sumber untuk mendukung pengambilan keputusan bisnis, kemudahan dalam mengakses atau menghasilkan informasi dan waktu respon sistem (cepat dan tepat waktu terhadap permintaan akan informasi) [2].

PT. PLN (Persero) Rayon Duri merupakan perusahaan yang bergerak untuk membantu masyarakat dalam pernyediaan jasa kelistrikan, dalam penyediaan jasa kelistrikan PT. PLN (Persero) Rayon Duri memiliki material kelistrikan disebuah gudang persedian untuk memenuhi kebutuhan konsumen. Untuk pengelolaan material listrik dibutuhkan adanya sistem yang mengatur tentang persediaan material listirik di gudang PT. PLN (Persero) Rayon Duri.

Sistem yang digunakan dalam pengelolaan material listrik PT PLN (Persero) Rayon Duri menggunakan sistem Administrasi Gudang Online (AGO) yang berfungsi untuk mengatur proses berjalannya administrasi gudang pada jumlah material masuk, keluar, pengiriman, penerimaan, dan pengembalian material yang sudah tidak bisa digunakan secara online atau berbasis teknologi.

Untuk menilai atau mengukur sebuah perangkat lunak maupun sistem informasi manajemen bida diukur berdasarkan beberapa indikator yang terdapat pada standar ISO/IEC 9126. Standar ISO/IEC 9126 adalah standar internasional yang diterbitkan oleh Organisasi Internasional untuk Standarisasi (International Organization for Standardization) atau disingkat ISO yang berguna untuk menilai kualitas perangkat lunak dalam pengukuran dan pengevaluasian [1].

Berdasarkan hasil jawaban kuesioner pendapat user terhadap penggunaan sistem AGO terdapat 6 masalah dan kekurang yang dimiliki oleh sistem administrasi gudang online (AGO) yaitu pada sub indikator security (kurangnya penjamin keamanan data 22\%), analyzability (kurangnya sistem analisa kerusakan sistem 13\%), atractiveness (kurangnya daya tarik user dalam menggunakan sistem 25\%), coexcistency (tidak mampunya sistem dibuka dalam satu web dengan sistem lainnya 37\%), maturity (rendahnya tingkat kematangan sistem 15\%), dan time behavior (perilaku sistem dalam mengindari kegagalan sistem $26 \%$ ) berdasarkan standar ISO 9126. Penelitian ini dilakukan betujuan untuk menemukan usulan perbaikan sistem administrasi gudang online (AGO) guna meningkatkan hasil persentase kualitas sistem di PT. PLN (Persero) Rayon Duri. Pengolahan data hanya menggunakan data tingkat kematangan (matuirty) dan tingkat perilaku waktu sistem (time bahavior).

\section{Studi Literatur}

\subsection{Sistem Informasi}

Sistem informasi adalah suatu sistem di dalam suatu organisasi yang mempertemukan kebutuhan pengolahan transaksi harian, mendukung operasi, bersifat manajerial dan kegiatan strategi dari suatu organisasi dan menyediakan pihak luar tertentu dengan laporan-laporan [5].

\subsection{Administrasi Gudang Online (AGO)}

Gudang online adalah administrasi gudang yang dikelola melalui aplikasi AGO (Administrasi Gudang Online). Monitoring stock material, permintaan material, pemakaian material, pengembalian material dan pengiriman material dilakukan secara online. Fungsi gudang online ini adalah untuk memenuhi kebutahan material yang dibutuhkan untuk operasional, PT. PLN (Persero) Rayon Duri dengan berbasis teknologi informasi.

\subsection{ISO/IEC 9126}

ISO/IEC 9126 adalah standar internasional yang diterbitkan oleh International Organization For Standardization (ISO) untuk mengevaluasi kualitas perangkat lunak. Model ISO/IEC 9126-1 mempunyai 6 karakteristik yakni functionality, reliability, usability, efficiency, maintability, dan portability. Setiap karakteristik mempunyai subkarakteristik masing-masing. Pada penelitian ini karakteristik yang diukur ada empat diantaranya functionality, reliability, usability, dan efficiency [3].

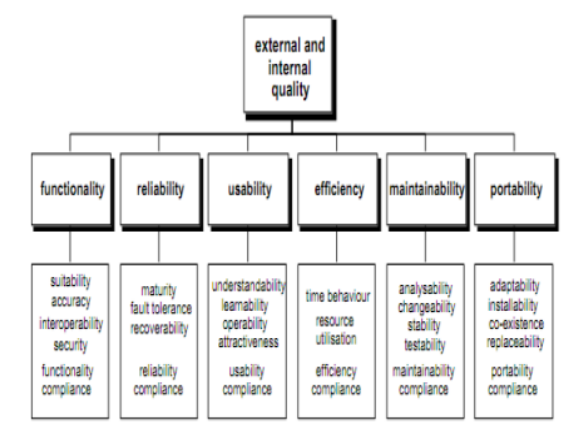

Gambar 1. Karakteristik dan sub-karakteristik ISO 9126 (Sumber: Kusuma, dkk, 2015)

\subsection{Uji Kualitas Sistem dengan Standar ISO 9126}

Dalam penelitian ini data yang diperoleh akan dianalisis dengan teknik statistik. Pertanyaan-pertanyaan dalam kuesioner menggunakan opsi jawaban model skala Likert. Selanjutnya nilai setiap item instrumen dapat dilihat dari perbandingan antara skor aktual dengan skor ideal. Skor aktual diperoleh melalui hasil perhitungan seluruh pendapat responden sesuai dengan nilai yang diberikan, sedangkan skor ideal diperoleh melalui prediksi nilai tertinggi dikalikan 
dengan jumlah kuesioner dikali jumlah responden, sehingga rumusnya adalah [4]:

$$
\text { Nilai instrumen }=\frac{\text { Sksor Alstual }}{\text { SkorIdeal }} \times 100 \%
$$

Persentase tersebut selanjutnya akan dikonversi kedalam predikat skala likert. Selanjutnya keempat persentase karakteristik tersebut akan ditotal untuk mendapat persentase keseluruhan. Rumus untuk menghitung persentase keseluruhan adalah sebagai berikut :

$$
\overline{\mathrm{x}}=\frac{\sum \mathrm{x}}{\mathrm{n}}
$$

Selanjutnya hasil tersebut dikonfirmasikan dengan kriteria yang telah ditetapkan, dapat dilihat pada Tabel 1 .

Tabel 1.

Kriteria Persentase Skor Tanggapan Terhadap Skor Ideal

\begin{tabular}{ccc}
\hline No. & \% Jumlah Skor & Kriteria \\
\hline 1. & $0 \%-20 \%$ & Tidak baik \\
2. & $21 \%-40 \%$ & Kurang baik \\
3. & $41 \%-60 \%$ & Cukup baik \\
4. & $61 \%-80 \%$ & Baik \\
5. & $81 \%-100 \%$ & Sangat baik
\end{tabular}

(Sumber: Leleila Dan Suwartika, 2018)

\subsection{Maturity Model}

Maturity Model merupakan model yang digunakan untuk mengukur tingkat kematangan (maturity level) pengelolaan teknologi informasi dalam suatu organisasi. Maturity Model terdiri dari lima tingkat kematangan pengeloaan TI, meliputi : tingkat 0 (non-existent), tingkat 1 (Initial/ad hoc), tingkat 2 (repeatable but intuitive), tingkat 3 (defined process), tingkat 4 (managed and measurable) dan tingkat 5 (optimised). Langkah untuk mengukur tingkat kematangan sebuah sistem yaitu [8]:

1. Menghitung Rata-rata jumlah kegagalan

$$
{ }_{\bar{x}}=\frac{\sum X i}{N}
$$

2. Simpangan baku (Sd) yang dapat dihitung dengan rumus sebagai berikut:

$$
\sigma=\sqrt{\frac{\sum(X i-\bar{X})^{2}}{N-1}}
$$

3. Standar error dapat dihitung dengan rumus sebagai berikut:

$$
\mathrm{S}_{\mathrm{x}}=\frac{\sigma}{\sqrt{\mathrm{n}}}
$$

4. Untuk menghitung nilai t dapat dihitung dengan rumus sebagai berikut:

$$
\mathrm{t}=\frac{\mathrm{n}-\underline{\mu}}{\mathrm{S}_{\mathrm{x}}}
$$

\subsection{Delay (waktu tunda)}

Delay (waktu tunda) adalah waktu yang dibutuhkan data untu menempuh jarak dari asal ketujuan. Delay dapat dipengaruhi oleh jarak, media fisik, kongesti atau juga waktu proses yang lama. Delay merupakan akumulasi berbagai waktu tunda dari ujung ke ujung pada jaringan internet. Dalam menghitung delay dapat menggunakan persamaan [7]:

$$
\text { Delay }(\mathrm{sec})=\frac{\text { Waktu Data Yang Dikirim }}{\text { Jumlah Data }}
$$

Tabel 2.

Parameter Nilai Delay

\begin{tabular}{cc} 
Parameter Nilai Delay & \\
\hline Delay $(\mathrm{ms})$ & Kualitas \\
\hline $0-150$ & Baik \\
$150-400$ & Cukup, masih dapat diterima \\
$>400$ & Buruk
\end{tabular}

(Sumber: Saputra, dkk, 2017)

\section{Metode Penelitian}

Penelitian ini bertujuan untuk menemukan usulan perbaikan untuk meningkatkan persentase kualitas layanan sistem administrasi online (AGO) berdasarkan standar ISO 9126.

a. Identifikasi sistem berdasarkan ISO 9126

Tahapan pertama ini mengukur tingkat kualitas sistem AGO dengan menggunakan kuesioner ISO 9126 untuk mengelompokan beberapa masalah yang terdapat pada sistem AGO.

b. Pengelompokan fitur sistem AGO

Tahapan kedua dalam standar ISO 9126 ini adalah mengelompokan fitur-fitur yang tidak ada dan ada namun dalam kondisi yang tidak baik.

c. Uji tingkat reliability (Keandalan)

Pada tahap ketiga ini sistem AGO diuji tingkat keandalannya dengan menggunakan pendekatan maturity model untuk mengetahui tingkat atau level sistem di sebuah perusahaan.

d. Uji tingkat efficieney (ketepatan) sistem AGO

Pada tahap 4 ini pengujian efficiency dilakukan untuk mengukur perilaku waktu sistem (time behavior) dalam keterlambatan input guna untuk melihat kategori keterlambatan masih bisa ditolerir oleh user atau tidak.

e. Usulan perbaikan sistem AGO

Pada tahap 5 ini sub indikator yang memiliki persentase rendah diberi usulan perbaikan guna meningkatkan kaulitas layanan sistem AGO.

\section{Hasil dan Analisis}

a. Uji Tingkat Reliability (Keandalan) sistem Administrasi Gudang Online (AGO).

Uji tingkat reliability (keandalan) sistem di uji melalui tingkat kematangan (maturity) sistem pada data kegagalan sistem saat sudah dilengkapi dengan fitur mode error. 
Tabel 3.

Jumlah Kegagalan Reservasi Sistem AGO User Gudang

\begin{tabular}{lcccccc}
\hline \multirow{1}{*}{\multicolumn{1}{c}{ USER }} & \multicolumn{5}{c}{ Jumlah Kegagalan } & \\
\cline { 2 - 5 } & \multicolumn{5}{c}{ Senin s.d jumat } \\
\hline Admin. Gudang & 3 & 1 & 4 & 2 & 4 & 14 \\
SPV. Pelayanan & 1 & 1 & 2 & 2 & 1 & 7 \\
$\begin{array}{l}\text { \& Administrasi } \\
\text { Manajer }\end{array}$ & 1 & 1 & 1 & 2 & 1 & 6 \\
& TOTAL & & & & 27 \\
\hline
\end{tabular}

(Sumber: PT. PLN (Persero) Rayon Duri, 2019)

Tabel 4.

Rekapitulasi Hasil Uji Maturity Level

\begin{tabular}{lcl}
\hline \multicolumn{1}{c}{ Tahap pengujian } & Hasil & \multicolumn{1}{c}{ Maturity Level } \\
\hline Rata-rata & 9 & $0,86=1$ \\
Keseluruuhan Data & & 1 initial ad hoc (permulaan): \\
Standar Deviasi & 19,1 & Sudah mulai ada penyusunan sistem \\
Standar Error & 11,04 & komputerisasi yang lebih terarah. \\
Uji nilai t & 0,86 & Tetapi Pengelolaan tidak \\
$\quad$ Hasil uji akhir $0,86=1$ & terstandarisasi.
\end{tabular}

(Sumber: Pengolahan Data, 2019)

Tabel 5 .

Tingkatan Model Maturity

\begin{tabular}{|c|c|c|}
\hline No. & Maturity level & Keteragan \\
\hline 1. & $\begin{array}{l}0 \text { non-existent (tidak } \\
\text { ada) }\end{array}$ & $\begin{array}{l}\text { Pengelolaan teknologi informasi masih } \\
\text { dalam tahap paling awal. Proses } \\
\text { manajemen tidak ada sama sekali. } \\
\text { Perusahaan belum mengetahui tentang } \\
\text { pengelolaan TI. Tidak terdapat proses } \\
\text { terkait sama sekali. }\end{array}$ \\
\hline 2. & $\begin{array}{l}1 \text { initial ad hoc } \\
\text { (permulaan) }\end{array}$ & $\begin{array}{l}\text { Sudah mulai ada penyusunan sistem } \\
\text { komputerisasi yang lebih terarah. } \\
\text { Tetapi Pengelolaan tidak } \\
\text { terstandarisasi. }\end{array}$ \\
\hline 3. & $\begin{array}{l}2=\text { Repeatable but } \\
\text { intuitive } \\
\text { (Pengulangan) }\end{array}$ & $\begin{array}{l}\text { Proses pengelolaan } \\
\text { dikembangkan. }\end{array}$ \\
\hline 4. & $\begin{array}{l}3=\text { Defined Process } \\
\text { (Terdefinisi) }\end{array}$ & $\begin{array}{l}\text { Prosedur telah distandarisasi, } \\
\text { didokumentasikan } \\
\text { dikomunikasikan melalui pelatihan. }\end{array}$ \\
\hline 5. & $\begin{array}{l}4 \text { = Managed and } \\
\text { measureable } \\
\text { (Dikelola) }\end{array}$ & $\begin{array}{l}4=\text { Managed and measureable } \\
\text { (Dikelola) }\end{array}$ \\
\hline 6. & $\begin{array}{l}5 \quad=\text { Optimised } \\
\text { (Dioptimalkan) }\end{array}$ & $\begin{array}{l}\text { Proses dalam perusahaan telah } \\
\text { disesuaikan dengan best practice, } \\
\text { praktek terbaik berdasarkan hasil } \\
\text { pengembangan secara terus-menerus } \\
\text { dengan perusahaan lain. }\end{array}$ \\
\hline
\end{tabular}

(Sumber: Salsabila dan Hadi, 2014)

Hasil uji maturity level menunjukan hasil akhir pada uji nilai t yang berada di tingkat 1 yang berarti sistem adminitrasi gudang online (AGO) Sudah mulai ada penyusunan sistem komputerisasi yang lebih terarah [6]. Tetapi Pengelolaan tidak terstandarisasi. Agar pengelolaan bisa terstandarisasi dibutuhkan sebuah evaluasi dan usulan perbaikan untuk beberapa fitur yang tingkat kematangan cukup rendah di operasikan agar tidak adanya proses kegiatan yang terhambat yang akan menimbulkan kerugian oleh pihak PT. PLN (Persero) Rayon Duri.
Tabel 6.

Output Uji Maturity Level Menggunakan Software SPSS

\begin{tabular}{lllll}
\hline \multicolumn{5}{c}{ One-Sample Statistic } \\
\hline ERROR & $\mathrm{N}$ & Mean & Std. Deviation & $\begin{array}{l}\text { Std Error } \\
\text { Mean }\end{array}$ \\
& 16 & 3,3750 & 6,38618 & 1,59655 \\
\hline
\end{tabular}

(Sumber: Pengolahan Data, 2019)

Tabel 7.

Output Uji Maturity Level Menggunakan Software SPSS

\begin{tabular}{|c|c|c|c|c|c|c|}
\hline \multicolumn{7}{|c|}{ Test value $=2$} \\
\hline & \multirow[t]{2}{*}{$\mathrm{T}$} & \multirow[t]{2}{*}{ Df } & \multirow[t]{2}{*}{$\begin{array}{l}\text { Sig. } \\
\text { (one- } \\
\text { tailed) }\end{array}$} & \multirow[t]{2}{*}{$\begin{array}{c}\text { Mean } \\
\text { Difference }\end{array}$} & \multicolumn{2}{|c|}{$\begin{array}{c}95 \% \text { confidence } \\
\text { interval of } \\
\text { difference }\end{array}$} \\
\hline & & & & & Lower & Upper \\
\hline ERROR & 0,861 & 15 & 0,403 & 1,73500 & $-2,0289$ & 4,7780 \\
\hline
\end{tabular}

\section{b. Analisis Output}

Berdasarkan hasil uji one sample t-test diketahui T Tabel $=2,920$ dan $\mathrm{T}$ Tabel $=0,861$. Berdasarkan hipotesis $(\mathrm{T}$ Hitung < T tabel) H1 ditolak, H0 diterima dan jika ( $\mathrm{T}$ hitung > T tabel) maka $\mathrm{H} 0$ ditolah $\mathrm{H} 1$ diterima, karena $0,861<1,735$ dan menyatakan $\mathrm{T}$ hitung $<\mathrm{T}$ Tabel maka hipotesis awal H1 ditolak dan H0 diterima. Hal ini diartikan bahwa jumlah kegagalan reservasi berpengaruh terhadap tingkat kematangan dan kualitas pelayanan sistem.

\section{c. Uji Tingkat Efficiency (Ketepatan) Sistem AGO}

Berdasarkan standar ISO 9126 uji delay masuk pada subindikator time behavior (Perilaku Waktu) untuk mengukur tingkat efisiensi nya sebuah sistem yang digunakan dalam perusahaan, sistem adminitasi gudang online (AGO) mengalami keterlambatan reservasi input 3 kali selama seminggu/jam kerja. berikut merupakan uji delay input material keluar pada hari selasa, kamis, dan jumat:

Tabel 8 .

Rekapitulasi Hasil Delay

\begin{tabular}{crr}
\hline No. & Jumlah keterlambatan & Keterangan \\
\hline 1. & 30 second & Baik \\
2. & 30 second & Baik \\
3. & 125 second & Baik
\end{tabular}

(Sumber: Pengolahan Data, 2019)

Tabel 9.

Parameter Nilai Delay

\begin{tabular}{cc}
\hline Delay (second) & Kualitas \\
\hline $0-150$ & Baik \\
$150-400$ & Cukup, masih dapat diterima \\
$>400$ & Buruk \\
\hline
\end{tabular}

(Sumber: Saputra, dkk, 2017)

Berdasarkan hasil uji delay dengan hasil keterlambatan input pada hari selasa selama 30 second/detik, kamis 30 second/detik, dan jumat 125 second/detik, dari hasil uji delay keterlambatan input data berada dalam kondisi baik, akan tetapi untuk menghidari atau untuk menghilangkan delay untuk penginputan data material kelistrikan diperlukannya 
beberapa evaluasi pada sistem administrasi gudang online (AGO) oleh IT support PT. PLN (Persero) Rayon Duri.

d. Analisa

Berdasarkan hasil uji reliability yang masih berada pada tingkat 1 pada keandalan dalam penggunaan sistem AGO bahwa pengembangan sistem masuk pada tahap sudah terkomputerisasi namun belum adanya standarisasi sistem yang baik, yang disebabkan adanya beberapa kerusakan yang sering terjadi pada sistem karena adanya jaringan koneksi yang tiba-tiba terputus akibat kabel atau konektor jaringan sudah tua dan perlu adanya pergantian kabel konektor yang baru.

Hasil pada waktu tunda penginutan material yang menunjukan bahwa keterlambatan masih bisa dikatakan bak dan dapat ditoleriri keterlambatannya yang disebabkan oleh server yang terlalu sibuk serta kapasitas penginputan yang terlalu banyak sehingga data input material listrik pada sistem administrasi gudang online (AGO) tidak bekerja semestinya.

Usulan perbaikan yang dapat diberikan untuk meningkatkan persentase kualitas layanan sistem adminisrtrasi gudang online (AGO) yaitu penjdwalan untuk perawatan sistem secara rutin dan berkala serta mengurangi kapasitas input perhari yang biasanya menginputan sebanyak 50 per material pada proses pengiriman, penerimaan, dan pengeluaran jumlah materiial masuk dan keluar menjadi 25 permaterial saja. Sehingga persentase awal yang hanya $26 \%$ dan $35 \%$ meningkat menjadi $50 \%$ dan $75 \%$ untuk kualitas layanan sistem adminitrasi gudang online (AGO).

\section{Kesimpulan dan Saran}

a. Kesimpulan

Kesimpulan yang dapat diambil dari pengukuran kualitas sistem administrasi gudang online (AGO) untuk meningkatkan kualitas layanan sistem adalah sebagai berikut Pemberian usulan perbaikan untuk persentase hasil kualitas rendah akibat kurangnya fitur pendukung kualitas sistem yaitu pada indicator.

Functionality dengan uji tingkat Keamanan (security) dengan hasil persentase $22 \%$ pada kondisi yang tidak baik dengan usulan perbaikan penambahan fitur keamanan sistem. Maintainability dengan uji tingkat Analisa sistem (analyzability) dengan hasil persentase $13 \%$ pada kondisi yang tidak baik, dengan usulan perbaikan penambahan fitur analisa sistem. Useability dengan uji pada Upgrade tampilan (atrractiveness) sistem administrasi gudang online (AGO) dengan persentase $25 \%$ pada kondisi kurang baik, dengan usulan perbaikan pemberian notifikasi Upgrade tampilan system. Portability dengan uji pembauran sistem (Coexistency) dengan persentase $37 \%$ pada kondisi sistem kurang baik, dengan usulan perbaikan pemindahan halaman web untuk bisa dibuka pada web browser mana pun.

Pemberian usulan perbaikan untuk persentase hasil kualitas sistem yang rendah akibat sering terjadinya kerusakan pada fitur sistem, yaitu terdapat pada indikator:

Reliability (kehandalan) dengan uji tingkat kematangan (maturity) sistem pada fitur mode error yang berada pada level
1 (initial ad hoc: sudah mulai ada penyusunan sistem komputerisasi yang lebih terarah, tetapi pengelolaan tidak terstandarisasi), dengan usulan perbaikan melakukan tindakan "perawatan pencegahan" seperti melakukan pemeriksaan, perawatan, penggantian komponen, repair dan overhaul, membangun help desk dan menyediakan lingkungan yang memumpuni untuk sistem sehingga kerusakan bisa diminimalisir.

Efficiency (ketepatan) dengan hasil uji tingkat time behavior (perilaku waktu) pada notifikasi yang menyebabkan adanya waktu tunda (delay) dengan hasil delay pada hari selasa, kamis, dan jumat sebesar 30, 30, dan 125 second (detik) yang berada dalam kondisi baik, meskipun dalam kondisi baik usulan perbaikan yang diberikan untuk mengurangi adanya waktu tunda yaitu mengurangi kapasitas input material perharinya. Dan mengganti kabel konektor jaringan agar server mampu melayani user dengan baik.

\section{b. Saran}

Saran yang dapat diberikan dari hasil penelitian ini adalah sebagai berikut:

1) Hasil pengujian kematangan (Maturity) sistem berada pada level 1, sehingga memungkin untuk dilakukan penelitian lebih lanjut agar level pada sistem administrasi gudang online (AGO) berada pada level 2-5, sehingga dapat menghasilkan sistem yang berstandar berdasarkan standar internasional.

2) Penelitian ini hanya sampai pada tahap usulan perbaikan dan belum dapat diimplemntasikan pada PT. PLN (Persero) Rayon Duri.

\section{Referensi}

[1] Banjarnahor, Dandles., Darwiyanto, E., Suwawi, DDJ. "Analisis Kualitas Sistem Presensi Pada Gracias Universitas Telkom Menggunakan Standar ISO 9126". Program Studi Teknik Informatika. Proceeding. Universitas Telkom. 2018.

[2] Fendini, Dian Septiayu., Kertahadi., Riyadi. "Pengaruh Kualitas Sistem dan Kualitas Informasi Terhadap Kepuasan Pengguna. Fakultas Ilmu Adminitrasi. Univeristas Brawijaya Malang. 2010.

[3] Kusuma, Selvia Ferdiana., Retri Enggar Pawerning., Umi Laili Yuhana."Pengukuran Kualitas Website Berdasarkan ISO 9126: Systematic Mapping”. Jurnal. Program Studi Teknik Informatika. Institut Teknologi Sepuluh Nopember. 2015.

[4] Lailela, Septi Noer Dan Suwartika, Rini. "Pengukuran Kualitas Perangkat Lunak Aplikasi Sisfo_Nilai Di Polteknik Piksi Ganesha Berdasarkan ISO 9126". Program Studi Manajemen Informatika. Jurnal. Politeknik Piksi Ganesha. 2018.

[5] Putra, Arie Setya dan Febriani, Ochi Marshella. "Sistem Informasi Monitoring Barang Pada Balai Riset Standarisasi Industri Bandar Lampung”. Jurusan Sistem Informasi. Jurnal Informatika. STMIK Mitra Lampung. 2013.

[6] Salsabila, Aufa dan Pranomo, Heru Hadi. "Analisis Tingkat Kematangan Sistem Informasi Rumah Sakit 
Aisyiyah Kudus".Program Studi Sistem Informasi. Fakultas Ilmu Komputer. Universitas Dian Nuswantoro. 2014.

[7] Saputra, dkk. "Penerapan Protokol MQTT Pada Teknologi WAN (Studi Kasus Sistem Parkir Univeristas Brawijaya)". Jurnal Informatika Mulawarman. Institut Teknologi Sepuluh November. 2017.

[8] Waseso, Bayu dan Wahono, Romi Satria. "Pengukuran Maturitas Pengembangan Perangkat Lunak Melalui Pendekatan Integrasi Capability Maturity Model Integration Dan Six Sigma”. Jurnal. STMIK Eresha. 2018. 